\title{
PEDIATRIA: MEDICINA PARA CRIANÇAS?
}

\section{Carlos Roberto Soares Freire de Rivoredo*}

RESUMO: O autor revê, em uma trajetória histórica, hipóteses formuladas sobre a existência de um campo do conhecimento médico - a Pediatria. Identifica um caminho que apenas foi possível mediante mudanças no estatuto social sobre as crianças e o papel que elas exercem na sociedade contemporanea. Fixando uma periodizaçáo a partir do século XVII e XVIII, constata uma sucessáo de eventos históricos que culminaram com o surgimento de um interesse científico sobre as crianças e seu .corpo para, ao fim, tornar ambos prisioneiros de procedimentos atrelados à mentalidade clinica. Por sua vez, presa ao paradigma eclético do conhecimento referido ao processo, saúde e doença, como assinala QUEVEDO (1989). As consequeências para as crianças e para as práticas sociais, entre elas a prática médica, estão expostas de forma a contribuir com elementos para futuros estudos sobre o campo térico e o aperfeiçoamento da medicina para as crianças.

PALAVRAS-CHAVE: prática médica; prática pediátrica; epistemologia

* Professor Assistente Doutor. Departamento de Pediatria. Área de Pediatria Social. Faculdade de Ciências Médicas da Unicamp. Campinas - Så Paulo. E. E.: carrivo@teranctcombr. Tel/fax: (O12)3521173. E. P.: Rodovia Nilo Máximo, 5752. Santo Antônio da Boa Vista. Jacarei (SP). CEP 12300-000 
A título de comentário inicial, gostaria de ressaltar o caráter sempre de começo e provisório dessas reflexões. Inicial porque o caminho que persigo nos últimos anos se defronta freqüentemente com dificuldades no plano das delimitações teóricas que têm se mostrado enormes para mim, forçando-me a estar sempre reiniciando o pensamento, sobre uma questão: qual seria, teoricamente, a especificidade do campo do conhecimento e das práticas correspondentes à Pediatria - essa invenção moderna da medicina para as crianças. Provisório exatamente pelo fato de estar me defrontando com uma definição teórica a ser gerada através das atuações práticas a partir das quais se forma seu objeto de estudo, enquanto fazer.

0 surgimento destas questões concretizou-se a partir de reflexões oriundas da minha prática. Uma revisão após mais de vinte anos de vida profissional em várias modalidades de exercício da Pediatria, desde o trabalho com os fazeres mais coletivos até as atividades em unidades especializadas de tratamento intensivo.

Além disto tento, mais recentemente, refletir sobre qual o papel que as crianças têm nos diversos momentos da prática médica derivada para elas. Muitas vezes, em que pese o esforço hoje mais freqüente de superação, vemos as crianças relegadas a um plano secundário durante o momento concreto da prática. Por exemplo, em muitos instantes, dadas as características da consulta pediátrica mais comumente vivenciada, existe uma dificuldade de comunicação com as crianças por parte dos pediatras que terminam, não sem conflito, por aproximarem-se delas apenas na ocasião de manipular seu corpo para efeito de execução do conjunto de procedimentos que contribuem para a elucidação diagnóstica. Pior, muitas vezes estes procedimentos são retraídos, somente para a aplicação de medidas subsidiárias com tecnologias armadas para efetivação do quadro que é o diagnóstico. A sensação que me provoca esta ordem de problemas é a de que, na relação médico-mãe-criança/paciente no lugar desta última, o duplo, não há nada a não ser um corpo/paciente a ser manipulado. Pode ser que soe dura esta afirmação e ela o é até para mim mesmo, mas coloco-a como questão a ser investigada, não se configurando em crítica moralista a essa prática que extrapola o campo da ética. Penso ser justificável debruçar-me sobre ela de maneira racional.

A questão à qual me refiro traz uma contradição detectável. Pensada a prática desta forma, o lugar que a criança tem durante 0 ato médico concreto em relação a ela mesma é muito pouco perceptivel; tornando-se objeto da consulta, seu corpo doente é 
transmudado em objeto da prática - aí reside o problema. Assim, esta questão inicial pode ser traduzida por uma outra que se mostra de forma multifacetada: "haveria, nos quase $\mathbf{2 0 0}$ anos de desenvolvimento da Pediatria, uma prática médica especifica para as crianças?" Tal questão se desdobra em outra: "para qual criança tal prática foi construída no tempo e no espaço?" "Quais as implicações para as crianças e os próprios médicos no desenvolvimento da relação médico-paciente/criança da adoção de um certo paradigma ${ }^{1}$ para pensar os problemas de saúde das crianças?"

Para discutir estas questões parto de dois pressupostos. O primeiro deles é que a prática médica é uma prática que, apesar de ser representada e divulgada como apenas técnica é, na verdade, também uma prática social (DONNANGELO \& PEREIRA, 1979). Nela, a sociedade se reproduz marcando um lugar e um papel para as crianças, historicamente determinados. O segundo deles é que, dos elementos constitutivos da prática médica - o objeto, os meios e os fins (MENDES GONÇALVES, 1984) - o primeiro deles é o ponto de partida para o estabelecimento dos demais, ou seja, do olhar que a prática lança sobre o objeto, do conjunto de redes de captação deste objeto é que se definem as maneiras de aproximação e os fins que a referida prática engendra. Ou seja, das diversas formas de considerar o objeto de uma prática (sociais, do conhecimento, ideológicas, etc) determinam-se modalidades possiveis de aproximação visando fins por sua vez também determinados pelas possibilidades de apreensão do objeto.

\section{PARA QUAL CRIANÇA TAL PRÁTICA FOI CONSTRUIDA NO TEMPO?}

A Pediatria moderna constituiu-se a partir de um movimento social no ocidente europeu que se difundiu por outras sociedades, enquanto parte da construção da Medicina moderna como um todo, a ponto de quase se globalizar hoje em dia. Tal movimento, lentamente, evoluiu a partir de uma confluência de situações econômicas - a ascensão e sedimentação do Capitalismo; modificações culturais - como o surgimento do Sentimento Moderno de Infância (ARIÈS, 1986), do indivíduo e da afirmação do espaço privado; e de interesses políticos - a organização do Estado Modemo (DONZELOT, 1989), que resultaram em um cuidado cada vez maior e uma importância cada vez mais acentuada para as crianças em nossa Sociedade.

1 Utilizo a noção de paradigma apresentada e problematizada por KUHN, Thomas S. A estrutura das revoluģões científicas. Perspectiva: São Paulo, 1979. 
Contudo, nesse deslocamento houve consequiências para elas decorrentes de uma articulação complexa entre as diversas práticas sociais que se deslocam em sua direção e dessas práticas com o lugar que as crianças passam a ocupar na nossa sociedade. Se, por um lado, o maior cuidado conseqüente à nova preocupação, trouxeThe uma maior sobrevida, por outro lado, o mundo infantil modemo tomourse uma oposição ao mundo adulto. Assim, como reflexo deste mundo adulto, as crianças e seu mundo tiveram sua vivência privatizada $e$ individualizada, assegurando a sobrevida mas acentuando e prolongando sua dependência. Além disto, esse mundo foi construído sobre modalidades ideais de pensar, ou seja, idealizado a partir de idealizaçōes sobre 0 mundo adulto, quer dizer, construido em decorrência de modelos erigidos a partir do mundo adulto, ele também idealmente pensado; este considerado como terminado, completo, no sentido da maturidade que lhe é atribuída; racional, ou seja, aquele que convive com a única racionalidade humana possivel; controlado em suas paixōes, pouco emocional, portanto; livre, no sentido do exercicio pleno do livre arbítrio; autônomo, com direitos e deveres reconhecidos; disciplinado, como produto da socialização. Este é o mundo do cidadão, daquele que conta e comanda; daquele que domina. O mundo infantil é exatamente o seu oposto: fugaz e provisório, incompleto, apaixonado e irracional, dependente e submisso, indisciplinado e não-socializado, ou seja, o mundo do nãocidadão, daquele que vale pelo vir-a-ser através da socialização que, por sua vez é determinada pelas expectativas que o mundo do adulto configura para a criança, espelhada na idéia que ele pensa ter sobre si, escamoteando suas próprias limitações e cegando-se para sua própria natureza ambígua e polissêmica. As crianças são submetidas a um sistema meritocrático (SARACENO, 1977), no qual valerá pela possibilidade de respostas positivas que puder dar em relação a expectativas afetivas e de retomo econômico entre outras, que se constróem sobre elas. Um sistema dirigido por especialistas (os agentes de socialização - principalmente médicos, educadores e moralistas), sob o controle panóptico do Estado e da Família, vigiadas e eventualmente punidas por deslizes que o mundo adulto forja como próprios delas, sob a alegação dos esforços para torná-la um bom adulto, normatizado e normalizado. As conseqüências desta visão da criança como um não-cidadão são tais que elas terminam sendo encaradas como sujeitos cujo pensamento não deve ser levado em conta, ou seja, desqualificadas, na medida em que são representadas como opostas a seres completos (os adultos), racionais, cidadãos.

Tal processo mostra um movimento de criação e evolução de uma mentalidade coletiva, ou seja, de um núcleo duro do pensamento coletivo manifesto de forma 
relativamente homogênea e automática nas maneiras de representar, nas atitudes e nas idéias, sobre as crianças. Tal sistema de mentalidade calca-se, em parte, numa determinada crença que assimila as crianças ao mito do bom selvagem, facilmente verificado em Rousseau, no Ėmile (ROUSSEAU, 1950). A partir do século XVIII, o estatuto social das crianças passa a incluir, entre outras coisas, a mentalidade de que elas sejam, por natureza, belas, puras, inocentes, assexuadas, identificadas com o Bem, atreladas às mulheres-mães, suas mães consangüíneas de forma inseparável. Além disto, lentamente, cria-se uma mentalidade coletiva que confunde o fenómeno da Infância, nitidiamente histórico, com as próprias crianças, como se elas sempre tivessem sido conforme a sociedade burguesa as enxerga.

Apesar disto, de maneira ambigua, delas se espera a bondade, mas também a crueldade, porque ainda sobrevive muito da crença medieval agostiniana da criança "viciosa", donde decorre sua disciplinarização pelo processo de socialização que, no entanto, não a apreende pelo que ela é, mas a opōe e subalterniza, pedagogicamente, ao adulto. Um processo que a personaliza², quer dizer, a acolhe, modelando-a, sem que se possa identificar nenhuma forma visivel de repressão, marcando-a com uma espécie de servidão que interessa à manutenção do status quo. Aparentemente, o sistema a desqualifica por que não visa a ela, mas ao adulto que ela poderá, idealmente, ser um dia submisso disciplinado, afetivamente instrumentalizado.

Tal personalização da criança é, na realidade, uma das conseqüências da privatização à qual ela é submetida, com a qual definem-se lugares de pertencimento das crianças que têm por referência diutuma a família. O núcleo familiar, ele mesmo formado a partir dos mesmos complexos movimentos sociais que puseram a modernidade, debruça-se sobre a criança protegendo-a do mundo exterior, mas restringindo seus espaços de convicio social extra-familiar àqueles delegados pela própria família. Assim, os contatos das crianças que não estejam "supervisionados" direta ou indiretamente pela família são, a priori, proibidos.

Ainda é este o tempo histórico das crianças e nele a Medicina vai atuar forjando o adulto que interessa ao sistema sem atinar para o que a criança mostra que é, desfigurando-a também em idealidades, desqualificando-a quando a confunde com seu

2 SCHËRER \& HOCQUENGHEM (1979) consideram que o processo de personalizaçáo constrói, a partir da crianca, a pessoa, ou seja, "a determinaço abstrata e artificial do individuo, que é muito mais a marca de sua servidio que de sua liberaçăo, no sentido de que todas as formas de responsabilidade social progressiva desembocam na exigencia de adogato de formas, quer de submisstio ou de derivaçio". 
corpo ou com sua doença, sem criar um raciocínio visando a cura que não se reduza a um fim em si, mas que apreenda seu corpo infantil como próprio e especifico, procurandoa, encontrando-a onde quer que ela esteja feliz ou não, em casa ou na rua, na escola ou fora dela.

Sobre esta criança historicamente construida é que a Medicina vai criar uma especialidade.

\section{QUAIS AS IMPLICAÇÕES PARA AS CRIANÇAS E OS PRÓPRIOS MÉdICOS NO DESENVOLVIMENTO DA RELAÇĀO MÉDICO/PACIENTE-CRIANÇA DA ADOÇÃO DE UM CERTO PARADIGMA PARA PENSAR OS PROBLEMAS DE SAÚdE DAS CRIANÇAS?}

A Pediatria, como especialidade médica, surge no final do século XVIII, no rastro das modificaçöes sócio-culturais próprias da Modernidade e das Luzes. Não foi possivel pensar uma especialidade médica para as crianças sem que estas tivessem um estatuto que Ihes desse um lugar social específico. Ao interesse social pelas crianças segue-se um interesse médico. Assim, não há uma Pediatria una, monolítica no tempo, que conclua de maneira autônoma sobre seu objeto e suas práticas.

Em outra ocasião (RIVORÉDO, 1995), pude observar momentos históricos distintos na formação do pensamento intrinsecamente pediátrico:

Um primeiro momento de afirmação da Pediatria. Desenvolve-se uma espécie de disputa no meio médico do final do século XVIII e princípio do século XIX sobre o pertencimento do cuidado médico para as crianças. De um lado aqueles que consideravam que a prática médica clínica era suficiente para dar conta das doenças das crianças. De outro lado, os que consideravam que elas possuiam especificidades que demandavam a formação de um médico especialmente treinado para delas cuidar. SEIDLER (1974) afirma que a decisão deste embate dependeu do movimento mais geral da atribuição de um estatuto social específico para as crianças. Em outras palavras, apenas foi possivel uma prática médica especifica para as crianças na medida em que esta especificidade estava dada na sociedade mais geral. A princípio, tal apropriação se organizou calcada numa certa aliança com as mães, afastando do cuidado com a saúde das crianças as figuras tradicionais da comadre, da aia, da ama e dos serviçais e curiosos em geral, apoiada nas idéias emergentes de que para cada criança o ideal seria que 
fosse cuidada pelas suas mães. Contudo, lentamente e em conjunto com outras práticas sociais para as crianças (como A Educação), o papel das mães cada vez mais se torna dependente de orientações médicas.

Um outro momento, quando a Pediatria se articula com a preocupação mais social sobre as crianças. Quando os papéis das diversas práticas sociais para com elas parecem se articular através de estratégias de cuidados que visavam, entre outras coisas, o retorno social de investimento, particularmente do Estado, perseguindo sua conservação. Dois exemplos dessas estratégias, do século XVIII, são a instituição dos hospícios para menores abandonados e da Roda, instrumento que mantinha 0 anonimato daqueles que necessitavam abandonar as crianças aos cuidados destas instituições. Apesar destes equipamentos não poderem ser considerados como instituições estritamente médicas, neles também se objetivava controlar as doenças e evitar a morte das crianças, cidadãos do futuro, que se prestariam ao desenvolvimento da Nação e da Raça.

Um terceiro, quando se funde ao movimento higiênico e, mais especificamente, à Puericultura. $O$ cuidado médico se articula às demais práticas sociais fornecendo legitimação científica para o cuidado com a saúde das crianças, privilegiando o controle das populações para o desenvolvimento da sociedade, particularmente as camadas mais pobres. Em meados do século XIX, já de certa forma com seu espaço institucional garantido, a Pediatria associa-se taticamente a outras práticas para dar resposta a um movimento de preocupação mais social com as condições de vida das crianças corroborando, por exemplo, a concepção que afirma um lugar extra-familiar único para elas: e escola. Esta instituição, de certa forma, quando radicalizada na estratégia do ensino básico obrigatório oficial, passa a ser uma espécie de cunha no poder da família sobre o processo de socialização das crianças.

Um quarto momento, quando aprofunda o discurso puericultor, que corresponde mais ou menos à primeira metade deste século. A Pediatria alimenta o discurso da Puericultura, apoiando-a cientificamente, mas de maneira impositiva, quer dizer, com ordens médicas que deveriam ser seguidas à risca, acompanhando os movimentos higiênicos mais gerais da época. Esta forma impositiva será, posteriormente, substituída por um tom mais de persuasão, mas que conserva os mesmos conceitos.

Por fim, quando adota o modelo da Medicina Tecnológica, conforme a compreendem DONNANGELO \& PEREIRA (1979) e SCHRAIBER (1993), antecedido 
de uma transição, quando a concepção alemã físico-química de Czerny se torna hegemônica, sugerindo que a saúde das crianças dependeria de um complexo educacional e nutricional. Segundo esta visão, privilegiava-se o cuidado com aspectos emocionais e alimentares das crianças como bastantes para manter seu estado de higidez. A conquista da saúde parecia reduzir-se aos cuidados com a Educação, dando conta do lado mais emocional das crianças, e da Nutrição, calcada nos conhecimentos científicos, recentes à época, sobre a físico-química dos seus processos digestivos.

Este novo deslocamento, que persiste até hoje, de adoção do modelo tecnológico que torna-se hegemônico no pós-Segunda Grande Guerra, adota para a Medicina das crianças as mesmas estratégias de partição do corpo e tecnificação do ato médico. Para a Medicina Tecnológica parece ter havido a criação de sua extensão para as crianças uma Pediatria Tecnológica.

Cabe ressaltar que, obviamente, tal periodização linear força os eventos numa visão lógica da aventura humana, mas esta é uma visão panorâmica da evolução que a Pediatria experimentou como especialidade médica, suprindo-se não apenas de tecnologia, mas também de uma certa maneira de olhar as crianças, no sentido, apenas visualizável a posteriori, da Pediatria que temos hoje. Cada um desses períodos tem suas rupturas e suas idas e vindas.

Há, portanto, percalços nesta trajetória, escolas que se sucedem e entram em conflito no tempo e que são substituídas sempre que um conjunto de idéias e saberes sobre a criança se torna hegemônico sobre os anteriores, funcionando como reflexos dos paradigmas da Medicina Geral, transmudados para a Medicina das crianças. Tais paradigmas se resumem no que QUEVEDO (1979) denomina de paradigma "eclético e biologista da doença” para o qual contribuem as visões classificatória, anatomoclínica, fisiopatológica e etiopatogênica da doença e da prática médica.

Na tentativa de aproximação - não sem crises - de uma prática médica para as crianças com as formas de pensar seu objeto, esta prática vai operar a mesma confusão que a Medicina fez entre objeto e fim, ou seja, do mesmo modo que a Medicina (e também porque é uma especialidade médica), a Pediatria objetivando o corpo doente da criança, da mãe e da família transforma-o em corpo da criança doente do pediatra, pelo caminho de considerar-se, a um só tempo, como arte de curar e conhecimento das técnicas e métodos de curar. 
Esta observação merece melhor esclarecimento. Para tanto recorro à análise de MENDES GONÇALVES (1984). A Medicina como uma prática social e considerada como trabalho, se conforma através da articulação de três elementos: a atividade para um fim, o objeto e os meios, que se determinam mutuamente.

No que diz respeito ao objeto, sem esquecer que os demais elementos interagem simultaneamente na conformação da prática, a prática médica se constitui pela discriminação no objeto das características que efetivam os objetivos.

Nas relações entre o objeto e esta prática há um processo de determinação recíproca. O objeto que determina a prática é, em parte, determinado por ela. Ou seja, o olhar que a medicina lança sobre o corpo humano doente é um olhar que cria, modificando, este mesmo corpo. Assim, o objeto portador da necessidade, como coisa natural se redefine em função do que a prática compreende sobre ele.

Num primeiro momento o objeto é submetido a uma dupla abstração. $O$ sujeito portador de uma necessidade sentida em seu corpo ao entrar em contato com a prática, através de seus agentes sociais, tem sua necessidade redimensionada pelas características da própria prática. Assim, o sintoma (ou a necessidade sentida pelo sujeito) é traduzida pelo sinal, passivel de adequação ao corpo de conhecimentos e aos sistema de pensamento médico. A partir daí ocorre uma segunda abstração, na medida em que os sinais são reorganizados em quadros que permitem a intervenção. Assim, o corpo doente (objeto da prática médica) anteriormente pleno da percepção que o sujeito tem de si mesmo (o "corpo doente do doente") se transmuta (parcialmente) no corpo doente do médico que é, este sim, o objeto da prática.- objeto de trabalho.

Contudo, mesmo assim, persiste algo de natureza no objeto porque o sujeito portador da necessidade persiste presente na relação. Exatamente por isto é que a transmutação é parcial. Nisto consiste o ponto de tensão na prática que se reflete por duas conseqüências, uma delas fundamental para a discussão que aqui desenvolvo, porque diz respeito diretamente às relações com seu obejto: "a medicina tende a confundir de maneira variável seu objeto com seu fim" (MENDES GONÇALVES, 1984:32). Destaca o fim, como arte de curar, o objeto, como corpo de conhecimentos sobre a doença e os modos de lidar com ela; e ambos, como arte e ciência de curar. Fixa-se no terreno da técnica descolada de seus aspectos mais sociais. Negligencia a "natureza" social do objeto e as implicaçőes e determinaçőes sociais dos demais elementos, tentando dar respostas técnicas às solicitaçöes do objeto, nesse sistema de pensamento apreensivel por uma certa maneira de pensar científica. A Pediatria vai seguir caminhos diversos no 
tempo desde sua formação. Inicialmente uma necessidade de definir-se se haveria ou não necessidade de criar uma especialidade médica para as crianças, polêmica que se instala no final do século XVIII e persiste ainda no princípio de século XIX, mas que termina por estabelecer a especialidade, legitimando-a.

No caso das crianças, esta relação se torna supertativa, na medida em que, por razões óbvias, na relação entre o médico e seu saber e a criança e seu corpo interpöese um intermediário, na maioria das vezes sua mảe, aumentando a distância entre 0 agente da prática e seu objeto.

Como é uma prática dependente das condiçōes materiais em que ela se dá ocorrem desdobramentos segundo o tempo histórico. Após um período em que se discute a pertinência de uma prática médica específica para as crianças e que corresponde ao final do século XVIII e inicio do século XIX (SEIDLER, 1974), a medicina para as crianças seguem os mesmos caminhos estratégicos da Medicina para adultos. No caso da Higiene, NOVAES (1979), LUNA FREIRE (1991) e BOLTANSKI (1974) mostraram os caminhos que o modelo puericultor seguiu desde sua origem, no esforço de regular a vida das populações, principalmente as mais pobres, passando pelo tempo da ordem médica mais impositiva, pelo da atenuação do discurso médico em direção à persuasão, até a perda de espaço da Puericultura, na Medicina, com uma certa permanência modelar no discurso emitido pelos organismos internacionais, como a Organização Mundial de Saúde (OMS), discurso que se manterá freqüente mesmo após o advento da chamada Medicina Tecnológica do pós-segunda grande guerra.

Parece-me que o discurso da Puericultura é emblemático da confusão que a Medicina faz entre objeto e fim. Senão vejamos. As crianças aqui são enxergadas do ponto de vista adulto, privilegiando para o que elas servem, ou seja, formar uma sociedade futura de homens vigorosos, sadios. Isto reforça a idealização do espaço do ser criança, impelindo o pensamento para considerá-la menor, miniatura, tabula rasa. Escapam a esta visão médica pediátrica as especificidades do objeto (exatamente pelo afastamento ao qual me referi anteriormente), que é prontamente idealizado; as prerrogativas para a criança são reduzidas ao fim para elas pretendido. Desta forma, ela se torna apagada, inencontrável nesse sistema de idealizaçöes.

Assim, o peso do processo de especialização da Medicina Tecnológica torna-se cada vez maior e, hoje, o que se vê é a subespecialização atingir também a própria Pediatria. Surgem, assim, diversas Pediatrias operando a mesma partição da Medicina 
de adultos, afastando-se do caráter essencialmente inteiro do objeto de sua prática, deslocando o conflito e a confusão para dentro de uma especialidade que tentava, em outros momentos, ater-se ao plano da unicidade do corpo doente da criança. Parece-me que a Pediatria, ao configurar historicamente seu conhecimento, segue o mesmo caminho que a Clínica. E nem poderia ser diferente, dada a pressão da realidade tecnológica, 0 peso do ensino da graduação, enfaticamente tecnológico e especializante, e a tradição, hoje já hegemônica, da residência médica setorizada por problemas, sistemas e órgãos. Assim, imagino poder dizer que hoje já há uma Pediatria Tecnológica, acompanhando o movimento dos últimos quarenta anos da Medicina para adultos.

Parece-me, por isto, (hipótese que ainda resta comprovar mais rigorosamente) que não há especificamente uma Prática Médica pediátrica, pelas razões que expus acima, isto é, a aproximação do corpo infantil, para além das tecnologias médicas a seu tempo, não leva em conta os seres que são as crianças. A Pediatria impõe-se assimilando da Clínica, em suas diversas versões, não apenas a tecnologia e os saberes, mas também o pensamento sobre o corpo. Se a Clínica - soberana de sempre - advogou por corporalizar o sujeito, a Pediatria o fez com o corpo infantil; se a Clínica - toda-poderosa conclui pela especialização, a Pediatria se subespecializa; se a Clínica - concepção que fundamenta a Prática Médica - assimila a tecnologia armada como operação privilegiada para lidar com as mazelas do corpo doente, a Pediatria o fará com o corpo infantil doente. Poderia parecer que a Pediatria perdeu uma visão antiga mais integral da criança e que a tenha perdido no período que se segue ao advento da Medicina Tecnológica. Penso que isto não possa ser sustentado. Ao contrário, de fato, esta unicidade ou globalidade na aproximação do corpo infantil jamais foi suficientemente presente a ponto de tornar-se parte da prática, quer dizer, se ela surge em um determinado momento como discurso, como no caso de Pedro de Alcântara que advogava pela visão integral da criança, a história nos mostra que este pensar não adquire força para superar o caminho que a história das práticas médicas para as crianças tomou. É neste sentido que a Pediatria opera uma certa antinomia em relação ao seu objeto. Ele é uno porque é a criança vista como ser, mas não o é porque necessita ser dividido em inúmeras partes desde o momento em que seu corpo é apreendido pela clínica e seus paradigmas tornando-se não mais o corpo doente da criança mas o corpo doente do pediatra, para utilizar a tipologia de MENDES GONÇALVES (1984).

Contudo, se há conflito, persiste de algum modo a peculiaridade geradora parcial do mesmo conflito, lembremos que o sujeito objeto da prática persiste existindo como 
sujeito. Penso que nesse conflito há elementos para equacionar as confusões e aproximar o mais possivel a prática do sujeito-criança. Imagino ser, ainda assim, a Prática Médica para as crianças uma Prática Médica peculiar necessitando lançar um novo olhar sobre seu objeto, transformando-o também em sujeito ativo da prática, visto em sua singularidade.

Tal aproximação renovada penso estar na adoção de um enfrentamento dos obstáculos epistemológicos que o paradigma gnoseológico moderno do processo saúde/ doença e da prática médica mostra, incorporando o social aos momentos concretos da prática, assimilando o que as crianças são, não como epifenômenos da história mas como ser historicamente determinado, mas sem abstrai-las demais. Uma tarefa como esta mostra sinais claros de sua complexidade, apesar de não carecer de necessidade. Um caminho poderia ser o de direcionar o processo de formação do médico de crianças ampliando os horizontes nos quais o fenômeno da infância e a criança que o subjaz são vislumbrados, arrefecendo a rigidez dos limites das disciplinas que dão suporte ao conhecimento médico sobre as crianças e incorporando maneiras diversas, de campos diferentes do conhecimento, na tentativa de formar um novo olhar sobre o objeto da prática pediátrica.

\section{REFERÊNCIAS BIBLIOGRÁFICAS}

ALCÂNTARA, P. Pediatria básica. São Paulo, Sarvier,1978.

ARIÈS, P. Historia social da criança e da família. In: LEGOFF, J., org. História nova. São Paulo: Martins Fontes, 1990. p.151-76.

ARIĖS, P. Historia das mentalidades. In: LEGOFF, J., org. História nova. São Paulo, Martins Fontes, 1990. p. 151-76.

ARIĖS, P. \& DUBY, G. História da vida privada. São Paulo. Cia das Letras, 1990. 5 v.

BARROS FILHO, J.M. O médico e a criança: estudos de puericultura e eugenia. São Paulo, Rev. Dos Tribunais, 1940.

BOLTANSKI, L. Puericultura y moral de clase. Barcelona, LAIA, 1974.

COLLOMP, A. Familias: habitaçóes e coabitaçס́es. In: ARIÉ, P. \& DUBY, G. Op. Cit.,1991. 5 v. V. 3.

COSTA, J.F. Ordem médica e norma familiar. Rio de Janeiro, Graal, 1989. 
DONNANGELO, M.C.F. \& PEREIRA, L. Saúde e sociedade. São Paulo, Duas Cidades, 1979.

DONZELOT, J. A policia das famílias. Rio de Janeiro, Graal,1989.

FOUCAULT, M. O nascimento da clinica. 3a. Ed. Rio de Janeiro: Forense/ Universitária, 1987.

FREIDSON, E. Profession of modicine: a study of the sociology of applied knowledge. New York, Dodd, Mead and Company, Inc.,1970.

FREIRE, M.M.L. Vidas desperdiçadas: a puericultura no discurso da OMS. Rio de Janeiro, 1991[Dissertação de Mestrado. IFF/FOCRUZ].

GÉLIS, J. A individualizaçâo da criança. In: DUBY, G. \& ARIES, P., org. História da vida privada: da renascença ao século das luzes. São Paulo, Cia Das Letras,1993. v. 3 p.311-30.

MARQUES, M.B. Contribuiçăo ao estudo do movimento de proteçăo à matemidade e à infancia. s I,1979. [mimeografado].

MENDES GONÇALVES, R.B.M. Medicina y historia: raices sociales del trabajo médico. México, Siglo Veituno, 1984.

NOVAES, M. H. Dutilh. A puericultura em questão. São Paulo, 1979. [Dissertação de Mestrado. DMP/FM/USP].

QUEVEDO, E. El processo salud-enfermedad: hasta una clinica y una epidemiologia no-positivista. s I,1989. [mimeografado].

REVEL, J. \& PETER, J.P. O corpo: o homem doente e sua historia. In: LEGOFF, J.; NORA, P. Historia: novos objetos. Rio de Janeiro, Francisco Alves, 1988, p.141159.

RIVORÊDO, C.R.S.F. de Cuidar e tratar de crianças: breve história de uma prática. São Paulo, Robe/Cabral, 1995.

ROUSSEAU, J.J. Emilio o la educación. In: Obras escogidas. Buenos Aires, EI Atheneo,1950.

SARACENO, C. La SOcializacion infantil como problema polfico. In: Experiencia y Teoria de las comunas infantiles. Barcelona, Fontanella, 1977.

SCHËRER, R. \& HOCQUENGUEM, G. Una novela infantil. In: Co-Ire: álbun sistemático de la infancia. Barcelona, Anagrama,1979, p.47-72.

SCHRAIBER, L.B. O médico e seu trabalho: limites da liberdade. São Paulo, HUCITEC, 1993. 


\section{PEDIATRIC: MEDICINE FOR CHILDREN?}

SUMMARY: The author reviews, in a historical trajectory, formulated hypotheses on the existence of a field of medical knowledge - Pediatrics. He identifies a path that was just made possible due to changes in the social statute on children and the social role they play in the contemporary society. Establishing a periodization starting from centuries XVII and XVIII, he observes a succession of historical events that culminated with the appearance of a scientific interest for children and their body so that, in the end, trasforms them both in prisoners of procedures harnessed to clinical mentality, tied to the ecletic paradigm of the knowledge referred to as the health/disease process, as marked by QUEVEDO (1989). The consequences. for children and social practices, among them the medical practice, are expressed in a way to contribute with elements for future historical studies that are deepened on theoretical pertinence and improvement of medicine for children.

KEY WORDS: medical pratice; pediatric pratice; epistemology 